\section{ON THE FREEZING OF LAKES ${ }^{1}$}

TN pursuance of investigations, now extending over some years, into the natural conditions of our seas and lakes, I took advantage of the recent frost to make some thermometric observations in fresh-water lakes covered with ice.

Most of the observations were made with one of Negretti and Zambra's "half-turn" deep sea thermometers, which proved to be a useful instrument for this species of inquiry. It was necessary however to fit it with a suitable inverting contrivance, as the apparatus supplied for this purpose by the makers is quite useless. When this thermometer was accidentally disabled, thermometers on the Millar-Casella type with certain improvements introduced by myself were used.

Observations were made in Linlithgow Loch at different dates, and in Loch Lomond on. January 28 and 29. The results are given in the accompanying tables.

Table I.-Loch Lomond

\begin{tabular}{|c|c|c|c|c|}
\hline \multirow{2}{*}{$\begin{array}{l}\text { Depth. } \\
\text { Feet. }\end{array}$} & \multicolumn{4}{|c|}{ Temperature, Fahrenheis, at Station. } \\
\hline & No. I. & No. 2. & No. 3 . & No. 4 . \\
\hline 3 & 33.00 & $33^{\circ} 5^{\circ}$ & $33 \cdot 60$ & $33 \% 70$ \\
\hline$\tilde{6}$ & $33^{\circ} 50$ & $33^{\circ} 70$ & 33.70 & 33.80 \\
\hline Bottom ro & - & - & 33.80 & - \\
\hline 12 & 33.70 & 33.80 & - & - \\
\hline 18 & 3395 & 33.95 & 一 & $33 \cdot 80$ \\
\hline 24 & 3405 & 3395 & - & - \\
\hline Bottom 27 & - & 3395 & 一 & - \\
\hline 30 & $34 \cdot 15$ & - & - & $33^{\circ} 95$ \\
\hline 36 & 34.35 & - & - & $34 \cdot 35$ \\
\hline 42 & 3460 & - & 一 & 34.55 \\
\hline 48 & $35^{\circ} 20$ & - & 一 & 35.05 \\
\hline Bottom $5 \mathrm{I}$ & - & - & 一 & $35^{\circ} \circ 5$ \\
\hline 54 & $35^{\circ} 45$ & 一 & - & - \\
\hline 60 & $36 \cdot 20$ & 一 & 一 & 一 \\
\hline Bottom 65 & $36 \cdot 30$ & - & - & - \\
\hline Mean ... & $34^{\circ} 4^{6}$ & $33 \% 74$ & - & $34^{\circ} \circ 5$ \\
\hline
\end{tabular}

TABLE II.-Linlithgow Loch

\begin{tabular}{|c|c|c|c|c|c|c|c|}
\hline \multirow{2}{*}{\multicolumn{2}{|c|}{$\begin{array}{l}\text { Depth. } \\
\text { Feet. }\end{array}$}} & \multicolumn{6}{|c|}{ Temperature, Fahrenheit, at Station. } \\
\hline & & No. I. & No. 2. & No, 3 . & No. 4 . & No. 6 . & No, 7 : \\
\hline & 3 & $34^{\circ} 90$ & - & - & $35^{\circ} 9^{\circ}$ & $36 \cdot 00$ & $3^{6 \cdot 00}$ \\
\hline & 6 & $35 \cdot 25$ & $3^{6 \cdot 10}$ & 36.00 & $36 \cdot 30$ & 36.60 & $36 \cdot 80$ \\
\hline & 12 & $37 \cdot 15$ & 36.80 & 36.85 & 36.80 & $37 \cdot 35$ & $37 \cdot 50$ \\
\hline Bottom & 16 & - & - & 37.40 & - & - & - \\
\hline Mud & 16 & - & 一 & 37.80 & - & 一 & - \\
\hline \multirow[t]{2}{*}{ Bottom } & $16 \frac{1}{2}$ & $38 \cdot 50$ & - & - & - & - & $\overrightarrow{7 \cdot \rho_{0}}$ \\
\hline & 18. & - & $36 \cdot 95$ & - & 36.90 & $37 \cdot 35$ & 37.80 \\
\hline \multirow{2}{*}{$\because$} & 24. & - & $37 \cdot 30$ & - & $37 \cdot 30$ & $37: 50$ & $38 \cdot 15$ \\
\hline & 30 & - & 3740 & $-\dot{0}$ & 37.40 & $37.9 \mathrm{c}$ & 38.30 \\
\hline & 36 & - & $37 \cdot 60$ & - & $37 \cdot 70$ & $38 \cdot 45$ & $39^{\circ} 00$ \\
\hline & 42 & - & -1 & - & $38 \div 40$ & 3980 & 4070 \\
\hline & 44 & 一 & $38 \cdot 60$ & $\because$ & E & - & - \\
\hline \multirow{2}{*}{$\begin{array}{l}\text { Mud } \\
\text { Mud }\end{array}$} & $\begin{array}{l}45 \\
46\end{array}$ & - & - & - & $39 \cdot 85$ & - & - \\
\hline & 47 & - & $39 \cdot 75$ & - & - & - & $一$ \\
\hline \multicolumn{2}{|c|}{ Mud $\quad 48$} & - & - & - & - & $4 I^{\prime} 70$ & $\left\{\begin{array}{l}42.05 \\
42.00\end{array}\right.$ \\
\hline \multicolumn{2}{|c|}{ Mean ... } & - & - & - & $37^{\prime} 22$ & $37 \cdot 83$ & $3^{8 \cdot 28}$ \\
\hline
\end{tabular}

I Substance of two papers'read before the Royal Society of Edinburgh on Januizy 20 and February 17, 1873 .
Had the freezing of the loch taken place according to the commonly received idea, that is, had its waters been first reduced uniformly throughout its depth to the temperature at which the density of water is a maximum, and the surface layer then cooled further until a coyering of ice was formed, we should have expected to have found the remains of this uniform temperature on examining the water after a firm coating of ice bat formed. Distilled water reaches its maximum density at $39: 2^{\circ}$ Fahr; and I naturally expected to meet with a considerable stratum of water at or near this temperature. Both in Linlithgow Loch and in Loch. Lomond there was a tendency to uniformity in the temperature of the water, but in Linlithgow this temperature was approximately $37^{\circ} \mathrm{F}$. and in Loch Lomond $34^{\circ} \mathrm{F}$. A single glance at the curves of the observations in these two lakes shows that they could never have been developed, if at the time of the formation of the first coating of ice the bulk of the water had been at a uniform temperature of $39^{\prime} 2^{\circ} \mathrm{F}$.

In order to explain the existence of this unexpectedly low temperature; $I$ at first imagined that there might be sufficient saline matter dissolved in the water to lower its temperature of maximum density. The presence of five parts of common salt in one thousand parts of water would have sufficed to lower this temperature to about $37^{\circ}$, and as the water of Linlithgow Loch was otherwise excessively foul; it appeared at first sight to be a likely explanation. It was not however verified by experiment. Although possessing a most offensive odour, the water was remarkably free from saline ingredients, and when its change of: volume at low temperatures was compared with that of distilled water in the same dilatometer no difference could be detected. Seeing then that the temperature of maximum density was the same as that of distilled water, it was evident that, before being covered with ice, the whole of the water had been cooled down much below that temperature, and that this effect had been produced in a still more marked manner in Loch Lomond.

Let us consider what would be likely to take place during the cooling and freezing of a lake such as the frozen part of Loch Lomond. The water would be cooled down gradually by radiation from the surface, and we may admit that at some date, probably early in December, the whole water from surface to bottom would have a sensibly uniform temperature of $39^{\circ} 2^{\circ} \mathrm{F}$. I believe that even in a very small lake there would be no date when the whole of the water would be uniformly at the temperature of maximum density, but it is a condition to which it would approximate in a greater or less degree, according to local circumstances. As the cold continued, circulation would be completely. stopped, and cooling would be confined to the surface-1ayer, supposing the climate of the surface to be absolutely:identical all over the surface of the lake. It is impossible that this condition can be fulfilled for more than an instant of time, for it would be disturbed by the slightesti movement of the atmosphere. As a matter of fact there is great diversity of climates even at points close to each other, causing among other effects great variations in the temperature of the surface water. Did lakes cool absolutely uniformly throughout their whole extent, there would be no reason why ice should begin to form in one part more than another, and the ice would begin to form at one and the same moment all over the lake,. which is: contrary to experience.

Let A B C (Fig. I) represent the bed of a lake in section, $D \mathrm{E}$ the surface of the water. At the date when the water has approximately the uniform temperature $39^{\circ} 2^{\circ} \mathrm{F}$ : D E will represent the isothermal of $39^{\circ} 2$. Now let the cooling go on and let the first ice appear, as it naturally would, at the edge. Let $\mathrm{E} F$ represent the first piece of ice, which for simplicity's sake we may suppose to have been formed suddenly, and let us consider the effect of its 
presence. This effect would be expressed graphically by the dipping of the isothermal of $39^{\circ} 2$, as at G, and the generation of those of temperatures intermediate between it and $32^{\circ} \mathrm{F}$. This alteration in the temperature means also an alteration in the density; and if we consider a vertical section through the ice at $\mathrm{H} \mathrm{K}$ and through the middle of the lake at $\mathrm{L} B$ we shall find the mean density at $\mathrm{L}$ greater than at $\mathrm{HK}$, and the result would be the production of convection currents. What takes place at $\mathrm{E}$ would take place on the other side at $\mathrm{A}$ also, and we should have a system of circulation which in broad outline would consist of surface currents from the sides towards the middle, and under currents from the middle towards the sides, somewhat after the inanner indicated in Fig. 2. The length of time that these currents would continue to flow before the lake was covered over with ice would depend on a number of local circumstances. The shape, size, and position of the lake would have much influence, and also the severity of the frost. However low the temperature of the air, the strength of the currents would always diminish as the water got cooled down, for the lowest available temperature is $32^{\circ}$ and the highest $39^{\circ} 2^{\circ}$. Hence the convection currents would be the strongest at the first formation of the ice, and would gradually, and at an increasing rate, get weaker as the general temperature of the water got lower. When the whole of the water was cooled to $32^{\circ}$ they would stop altogether.

It is therefore certain that in the water of a frozen lake we must find a tolerably uniform temperature, and this temperature must lie between $39^{\circ} 2^{\circ}$ and $32^{\circ}$. In order that either of these extreme temperatures should

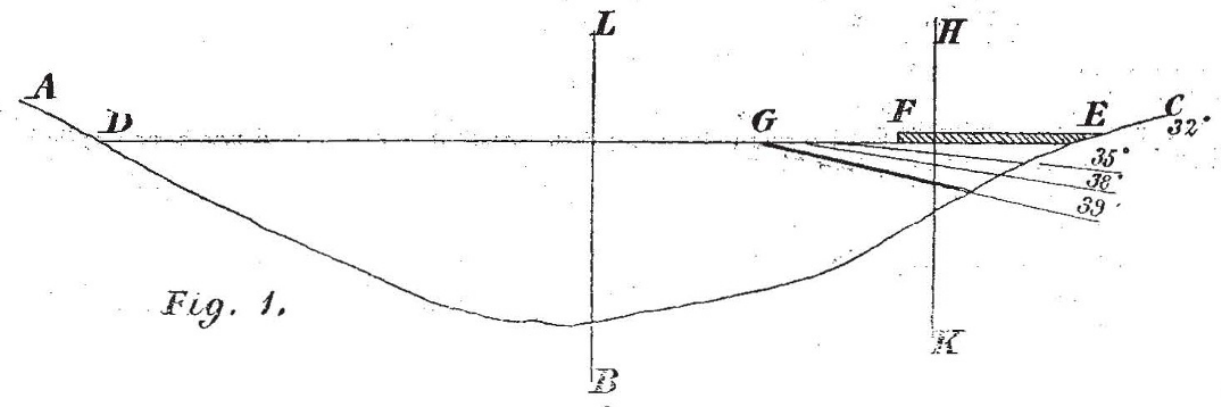

prevail, the weather would require to be of a very exceptional character. Admitting that the water had been cooled to a uniform temperature of $39^{\circ} 2^{\circ}$, this temperature could be fixed only by a sudden frost of extraordinary and probably unknown intensity. As the convection currents become weaker the more nearly the temperature of the water approaches $32^{\circ}$ it would require the least possible frost during an infinite winter to reduce the temperature of the water to $32^{\circ}$ before it was covered with ice. The uniform temperature of $32^{\circ}$ however could be produced in another way, namely by the cooling of the water after it was covered with ice. This condition is probably not uncommon in shallow lakes in very cold climates.

In general, in climates such as our own, an intermediate temperature would prevail. In the Balloch basin of Loch Lomond this temperature was found to be about $33^{\circ} 9^{\circ} \mathrm{F}$. In Linlithgow Losh it was much higher, about $37^{\circ} \mathrm{F}$. The lake will remain open with an ice-fringe along the side as long as the water leaves the ice-edge with sufficient velocity to mix with the warmer water off shore before freezing under the influence of surface radiation. As soon however as this velocity is reduced so far as to enable the frost to overtake the water as it leaves the ice-edge before mixing with the warmer water the propagation of ice from the fringe out into the middle of the lake will take place with great rapidity, and a single night will often be sufficient to cover a large lake.

From the moment of the formation of the complete ice covering, the water is subjected to a uniform climate, its surface being everywhere in contact with ice; and it is only under these conditions that the whole of the lake can be said to be exposed to an identical climate.

Hence we see that, even admitting that a uniform tempe-

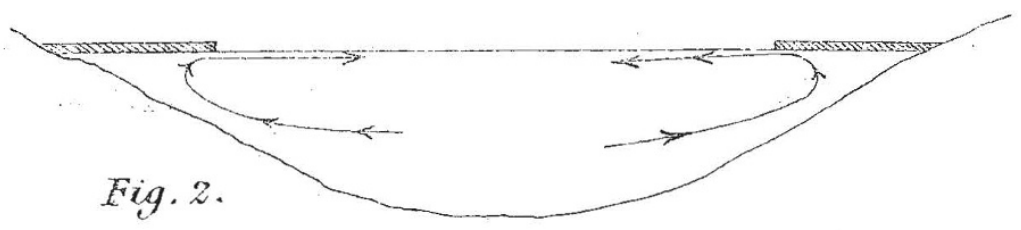

rature of $39^{\circ} 2^{\circ}$ had previously existed, the whole of the water would be very considerably cooled down before it could be covered with ice, and the extent of this cooling would de. pend on local circumstances of position and climate, so that the final temperature of the water would be different for different lakes in the same winter, and for the same lake in different winters. The body of the water of a lake would be cooled more when it has been frozen by a moderate and comparatively long continued frost, than when the ice has been frozen quickly by very severe frost. For the more severe the frost the sooner will it be able to overtake the water leaving the ice fringe; in other words, the stronger will be the current which it will be able to arrest; and the greater the head which it will be able to stem. But the head which causes the current, is caused by the higher temperature of the open water as compared with that under the ice. Hence the mo:e severe the frost, the higher will be the temperature which it will be able to fix. Let us now consider the causes which would tend to alter the temperature fixed by the ice covering.

In the first place there is alteration in the thickness of the ice and conduction from it downwards. The effect so produced would be concentrated in the surface layer, and its nature can be easily imagined.

In a large lake like Loch Lomond there is, even in severe weather, a considerable amount of change of water going on. The river Leven, which leaves it at Balloch, is navigable for small vessels, and a number of not inconsiderable streams fall in at different parts of the loch. The ice extended from the lower end at Balloch up to Luss, where it terminated in a miniature cliff which swept in a curve from the Dumbartonshire shore to the island of Inchlonaig and thence in another curve to the Stirlingshire shore. It is easy to see that the streams which fall 
into the lake in its lower part when it is covered with ice, must supply water at $32^{\circ} \mathrm{F}$; for even if it were at a bigher temperature while forming part of the stream, it would, by impinging on the edge of the lake ice, be cooled down before being able to mix with its waters. It would thus enter the lake at $32^{\circ}$ and would spread itself out immediately under the ice, and its effect on the temperature of the water would be similar to that produced by the thickening of the ice and conduction from it.

The excess of water which falls into the upper and open part of the lake must also find its way under the ice to the outlet. In order to estimate its effect, we must consider the conditions obtaining at the terminal edge of the ice stretching across the lake. We have already discussed what takes place when the first ice fringe forms at the sides of a lake, and we may look on the ice covering the lower and shallower part of the lake, as the fringe on that side of the upper and deeper basin. The same convection currents which we have described will take place here, giving us a surface current from the ice, and an under current towards the ice, now the water in finding its way under the ice to the outlet, will take the easiest way possible, and as it will find itself retarded or opposed at the surface near the ice edge, and assisted near the bottom by the convection circulation, its supply will be delivered by preference as an under and therefore comparatively warm current. Off the edge of the ice I found the water at $8 \frac{1}{2}$ fathoms $37^{\circ} 2^{\circ}$, and in $17 \frac{1}{2}$ fathoms $374^{\circ} \mathrm{F}$. In accordance with the same principle of greatest easiness, this water would penetrate into the frozen basin by the deepest existing channel. The lower or frozen basin is separated from the upper and open one by a remarkable chain of islands separated from each other by channels everywhere less than there, and indeed hardly anywere more than two fathoms deep. The two channels however next the main land are each five fathoms deep, and it is through them that the bulk of the water finds its way. This was shown in a very singular way by the existence of a space of open water stretching from the main land to the nearest island over the shallowest part of the channel on the Dumbartonshire shore, there being thick strong ice over the deep water on both sides. In its passage over the ridge which rises very steeply, the warm water is thrown up near the surface and its supply is sufficient not only to preserve this space of open water, but also to raise the temperature of all the water of a depth greater than five fathoms in the lower basin.

In the case then of a lake only partially frozen, the temperature of the water under the ice is lowered by the drainage entering where it is frozen and is raised by the water supplied from the open part provided the channels connecting the two parts are not too shallow.

In Linlithgow Loch which was entirely frozen over, the very great rise of temperature near the bottom was caused by the immense quantity of filth contained in its water and in the mud at the bottom.

J. Y. BUCHANAN

\section{ON THE BURSTING OF THE GUN ON BOARD} THE THUNDERER ${ }^{1}$

I $N$ the interval which elapsed between the bursting of 1 the gun and the report of the Committee much thought and some trouble has been expended in divining the possible causes which might, under one set of circumstances or another, have led to such a result. It now appears, however, that, different as have been the various suggestions, they all resembled each other in one particular, namely, that they were all wrong.

It is to be hoped, however, that all the ingenuity that has been expended will not have been thrown away, and that some improvement may result from the pointing out

${ }^{x}$ Read before the Lit. and Phil. Society of Manchester on February 18, by Prof. Osborne Reynolds, F.R.S., Professor of Engineering, Owens College, Manchester. of such numerous defects. That in some respects, such as the increasing twist and the sudden steps or shoulders on the outside of the gun, the present system is defective, is shown quite apart from the recent accident; and although it now appears that the moving forward of the shot as the rammer was withdrawn had probably nothing to do with this accident, it cannot be considered satisfactory that this moving forward should be so much the rule as it is shown to have been in the experiments recently undertaken.

Although at first sight it may appear that the fact of the gun having been loaded with two charges of powder and two shot is amply sufficient to explain the bursting, it may not be useless to examine somewhat closely into what would result under such circumstances. The bursting of a 38-ton wrought-iron gun is an experiment of which we should make the most as we cannot expect to have it often repeated.

From the first accounts of the accident it appeared as though the gun had simply broken in two, like a carrot, at the first step, and that the front half had gone into the sea. Such a failure would not have implied an excess of pressure. It might have been caused by a great end strain such as would have resulted had the shot jammed when in full career and carried away the fore part of the gun, or it might have resulted from the gradual weakening of the section of the gun at the shoulder owing to the different degrees of expansion immediately before and immediately behind. One or other of these causes appeared to afford the most probable explanation of the phenomena as described in the early accounts. In various subsequent reports, however, it was stated that fragments of the fore part of the gun were blown about in all directions. So that the gun, instead of having simply broker in two, must have burst like a shell in front of the first shoulder. This fact placed the phenomena in an altogether different light. The explosive bursting of the zone of the gun into fragments implied an enormous excess of pressure at this point of the gun.

In order to cause the tube of the gun to burst longitudinally at all would require several times the normal pressure, and the breaking up of the wrought-iron tube into fragments would show that the force was largely in excess of what was necessary to burst it.

After seeing these reports it appeared certain that the gun had been subjected, at the point of rupture, to a pressure enormously excessive, and the question became whence could such a pressure have arisen? To me it appeared that nothing short of such an action as might, with a detonating fuse, result from the explosion of guncotton or dynamite would explain the breaking of the gun into fragments. Had the shot become jammed the pressure might have been raised sufficiently to burst the gun, but with pebble powder even this seemed doubtful, and such an action seemed altogether inadequate to explain the breaking of the gun into fragments. It appeared, therefore, that there was but one conclusion to be drawn--there had been something abnormal in the loading. Had the gun been loaded with small grained powder, gun-cotton, or dynamite, instead of pebble powder, such a result might have been produced; but then, the gun would, if it had burst, have burst at the breach unless the shot had slipped forward, and that there should have been two accidents appeared highly improbable. Besides, it was necessary to consider what sort of a mistake was most likely to have occurred; and the only possible mistake that could have been made on the spot appeared to be that of double loading.

The fact that if two complete charges were put into the gun, the powder of the second charge would be directly beneath the point of rupture appeared in favour of this. the easiest mistake. But would, supposing the powder to have been pebble powder, the pressure from the two charges have been sufficient to cause the result? At first 